\title{
A stance against forced retirement
}

18 Mar 2020

Taken from the March 2020 issue of Physics World. Members of the Institute of Physics can enjoy the full issue via the Physics World app.

Paul Ewart says it is unfair to force active physicists to retire to "free up" positions for younger scientists or to improve diversity - when there is little evidence that it does so

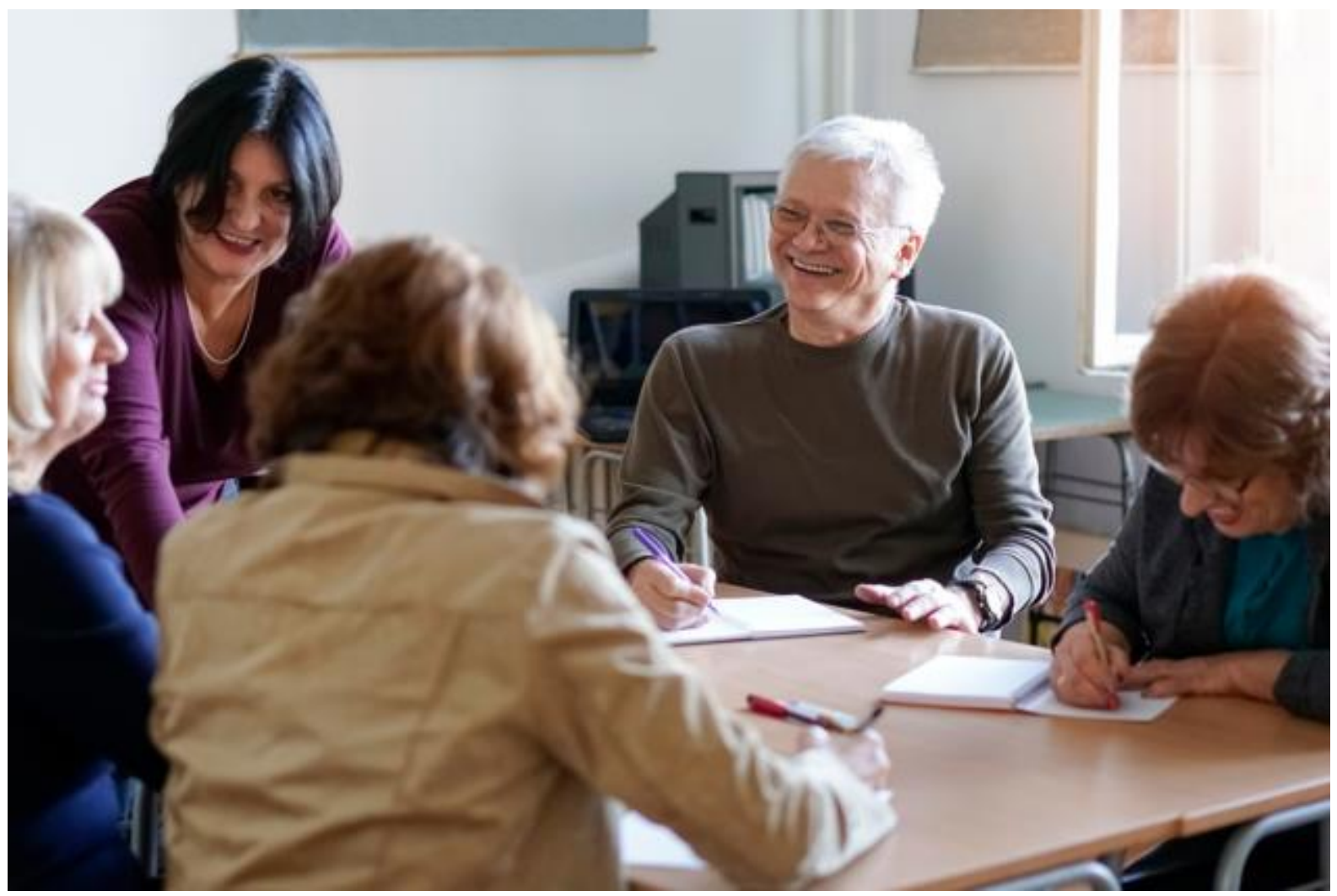

Stepping aside: some universities claim that imposing retirement can help create vacancies that improves gender diversity as well as opportunities for younger academics. (Courtesy: iStock/BakiBG)

Making reasonable estimates is a core skill for a scientist. When I interviewed candidates to study physics at the University of Oxford, I'd ask them a variant of the "Fermi problem". Enrico Fermi famously asked students to estimate the number of piano tuners in Chicago, whereas my version asked how many barbers there are in Oxford. Reasonably accurate answers can be obtained using sensible approximations and any available data (Oxford has a population of 120,000 , half go to a barber and do so once every six weeks, etc).

I found myself doing a similar calculation when faced with forced retirement as a physics professor at Oxford in 2015. Although the UK's 2010 Equality Act outlaws fixed-age retirement, an employer can impose an Employer Justified Retirement Age (EJRA) but it must show that it is a proportionate means of achieving some legitimate aim. When my request for a further extension of employment to continue my active and funded research was 
refused, an employment tribunal upheld my claim of age discrimination. The university is appealing the judgement (bit.ly/2SssP9s).

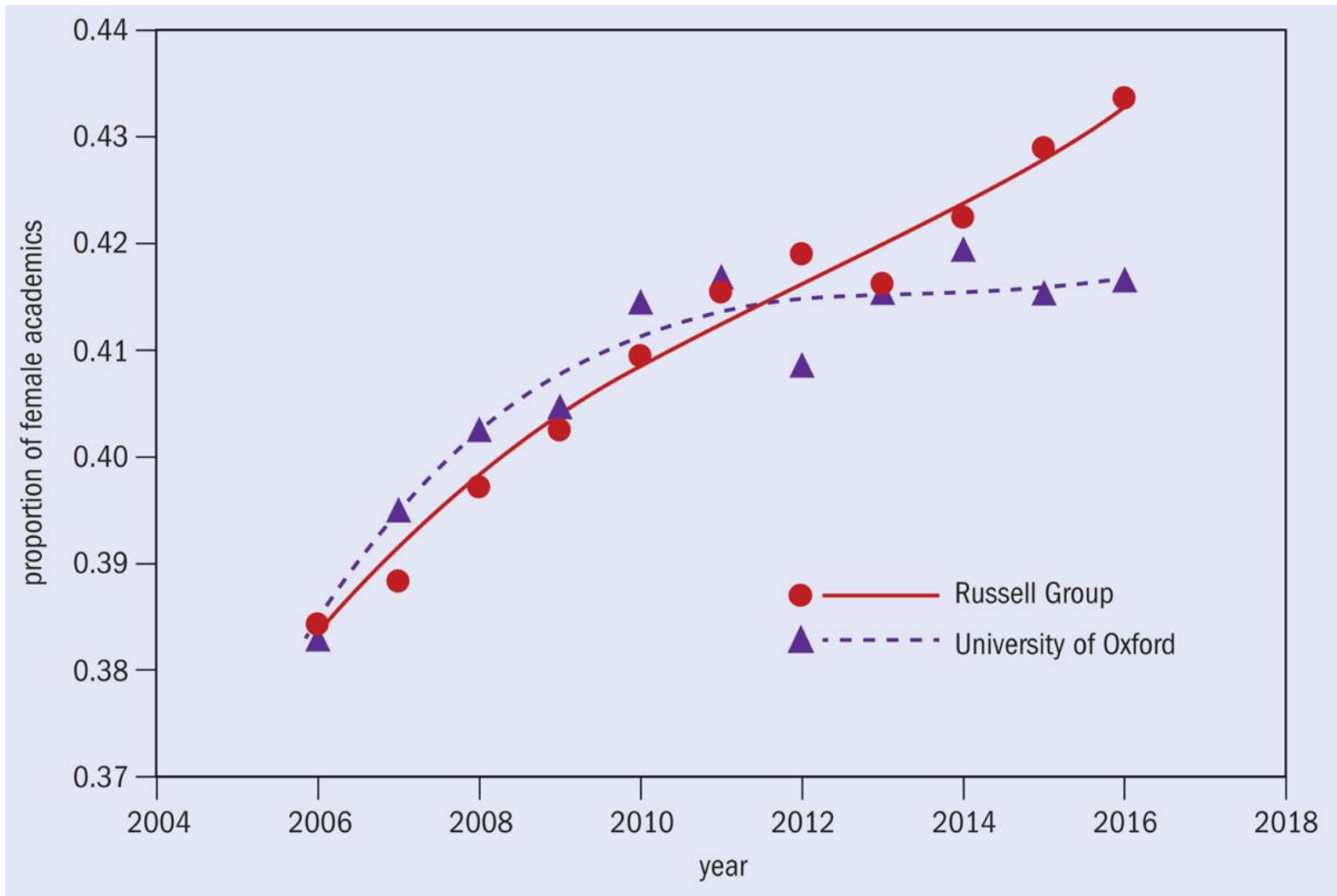

Look at the data: The average proportion of female academics at the Russell Group of UK universities shows a steady increase from 2006 to 2016, but at the University of Oxford that rise stops from 2011.

Oxford claimed its EJRA policy, by creating vacancies, improved gender diversity and opportunities for younger academics. I questioned that it was proportionate by doing a Fermistyle estimation - using reasonable approximations and available data - of the extent to which it could achieve these aims. An EJRA changes only the rate of vacancy creation by bringing forward some vacancies that would occur anyway - no-one works forever.

Assuming, initially, that everyone works until retirement and extends their career by $10 \%$, preventing such extensions by an EJRA changes the vacancy rate by $10 \%$. However, data show that, at Oxford, only $40 \%$ of employees stayed until retirement and then, at most, only $50 \%$ of them wished to extend. The resulting change of $2-4 \%$ in the vacancy rate was judged "trivial" by the tribunal and not proportionate to the heavy discrimination involved.

When Oxford introduced its EJRA in 2011, it committed, but failed, to monitor its effectiveness by comparison with the rest of the Russell Group of UK universities, none of which - except Cambridge - operates forced retirement. Using data from the Higher Education Statistics Agency I was able to show that there was no evidence of any impact on gender diversity (see figure above). The effect on opportunities for younger people was similarly trivial as indicated by the proportion of academics aged over 67 . These results, confirmed by rigorous statistical analysis by Oxford's own statistics consultant, the late 
Daniel Lunn, are entirely consistent with the trivial size of the EJRA's effect on vacancy creation.

\section{Loss of opportunities}

It cannot be right to dismiss active physicists, or indeed any productive academic, at some arbitrary age. It is traumatic to be forcibly retired, especially when one's work is still in full swing and there are new ideas to be explored. The "emeritus" status offered by Oxford, instead of full employment, is of no use to experimental scientists who need a research team and principal-investigator status to apply for their own research funding.

It is simply ageism that underlies many of the arguments used to justify mandatory retirement. Age is often used as a proxy for competence and this lazy stereotype feeds off the myth that scientists have their best ideas when they are young. Indeed, studies have shown that a scientist's most impactful work can occur at any stage in their career.

The argument that younger people gain from the "freeing up" of posts ignores the loss of opportunities for graduate students and postdocs provided by experienced, grant-winning, senior academics. It is ageism that sees a 40 -year-old as "filling" a post whereas a 65 -yearold is "blocking" a post. Apart from providing the dignity and fulfilment of employment, there are general imperatives for people to work longer, including the growing pension burden and increases in life expectancy. Recent studies by the World Health Organization also highlight the physical and mental health benefits of working longer. The International Standards Organization is currently conducting a project on the economic and social benefits of an "age-inclusive" workforce.

Ageism is endemic in our society and attitudes persist that would be recognized as shameful if they related to race, religion or sexual orientation. The University of Oxford's claim that dismissing older academics is necessary to maintain its high standards is simply ageism, implying that academic performance deteriorates with age. If retirement policies are to be truly evidence-based, they need to be justified by reasoned estimates of proportionality that are consistent with the available data.

Paul Ewart is a physicist at the University of Oxford, UK, e-mail paul.ewart@physics.ox.ac.uk 